Mitos e Imagens Arquetípicas na Mídia: a construção narrativa em 0 Senhor dos Anéis

Myths and Archetypical Images on Media: the narrative construction on The Lord of the Rings

Magno Medeiros

Professor Adjunto da Faculdade de Comunicação e Biblioteconomia/UFG

E-mail: magnomedeiros@uol.com.br.

Gustavo Pereira Portes

João Paulo Cândido de Oliveira

Murilo Luiz Ferreira

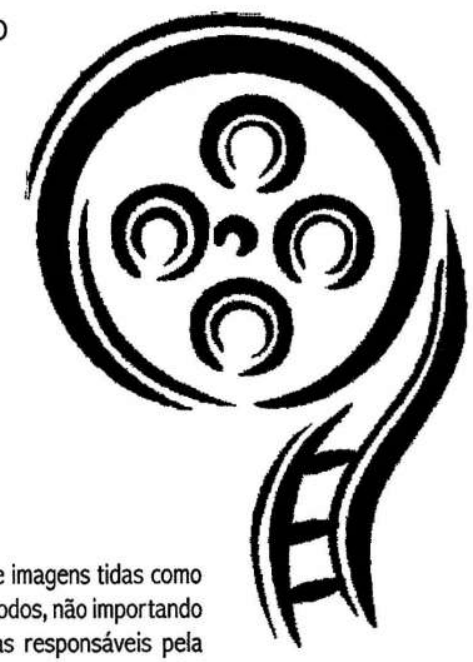

Resumo

Esta pesquisa tem por objetivo estudar o comportamento do público perante imagens tidas como pertencentes ao inconsciente coletivo, que, segundo Jung, estão na mente de todos, não importando classe social, nem religião, raça, etc. Essas imagens arquetípicas serão as responsáveis pela estruturação da psique, estabelecendo os caminhos a serem seguidos e como andar por eles. Foi feita uma entrevista com alunos de escolas públicas e privadas. Após a coleta, os dados foram analisados de acordo com a classificação, faixa etária e classe social, e, posteriormente, foi traçado um paralelo entre eles.

Palavras-chave: Mitos, Arquétipos, Construção Narrativa, Senhor dos Anéis, Imagens Arquetlpicas, Psique.

Introdução

Com o avanço dos estudos na área da psicologia, no século passado, muitos assuntos, antes tidos como supérfluos ou mesmo ditos como inexplicáveis, começaram a tomar uma nova dinâmica. A psicologia, seguida pela psicanálise, e então pela psicologia analítica, começou a desvendar a mente humana e a razão, explicando os modos de agir, o comportamento, a construção do caráter, o temperamento e a personalidade do homem.

Jung, ainda em suas pesquisas sobre o inconsciente coletivo, partirá para um ponto mais complexo, ao pensar que todas essas imagens, novamente exemplificada pelo Édipo, têm uma raiz comum, que é a mitologia.

Mitos narrados em todos os cantos do mundo, ao serem analisados demonstraram coinci-dências impressionantes, que, segundo Jung, seriam justificadas exatamente pelo inconsciente coletivo. Outros teóricos, dentre eles Joseph Campbell, estudaram exatamente isso, a Mitologia Comparativa, que trata de achar as semelhanças entre os mitos do mundo, e não as diferenças.

Isso tudo está no mais profundo da psique humana, desde a idade primitiva até os dias de hoje. Essas imagens atiçadas causam efeitos no homem, e das quais a mídia atual usa e abusa. Com um bom domínio desses estudos, é possível fazer filmes, novelas, propagandas, etc., que se encaixarão bem ao público, e é este o motivo desta pesquisa: debater sobre o uso dessas imagens pela mídia atual e de como elas chegam à cabeça de quem as vê.

Sobre mitos, arquétipos e a narrativa

As entrevistas foram realizadas em dois colégios, um era público e o outro privado, com estudantes do nível médio.

$\mathrm{Na}$ escola pública, foi reparado que os entrevistados não tinham tantas lembranças sobre o que aconteceu no 
filme, pois fizeram várias perguntas sobre cenas e personagens; mesmo assim, são válidas as respostas, pois foram pertinentes às indagações do questionário.

$\mathrm{Na}$ escola particular, os entrevistados mostraram maior conhecimento do filme e dos personagens, referindo-se a eles com maior certeza. As diferenças de classe entre esses alunos e os do outro colégio mostram que o conhecimento cultural também diverge completamente. As respostas também mudam, mas a essência continua a mesma.

Verificou-se que cada um teve uma identificação pessoal com cada personagem, levando em consideração o ego pessoal de quem assiste. O filme 'O Senhor dos Anéis' é rico por ter uma gama enorme de personagens, e cada um, à sua maneira, lida com problemas iguais.

A variação de personalidades e a personificação de arquétipos facilitam a identificação dos espectadores com o filme. Não era esperado que as respostas fossem muito parecidas, em virtude principal da grande quantidade de personagens encontrados no filme, mas os exemplos dados para explicar as escolhas sempre refletem projeções de realidades internas de cada um.

Levando isso em consideração, pode-se dizer que algumas características são sempre imprescindíveis para a construção adequada de uma narrativa, como as que foram mais lembradas: a amizade, o amor, a alegria, a determinação (objetivos determinados), a figura do salvador e, principalmente, a presença, que é o mais importante para realçar as características, sejam elas quais forem, de determinado personagem.

As atitudes mais visíveis e a relevância dos personagens na narrativa são os fatores primeiramente analisados por quem assiste a um filme. Legolas e Aragorn somam juntos $50 \%$ das respostas dadas.

Legolas só foi citado na escola pública, onde não houve surpresa nas respostas, sendo citados apenas personagens mais visíveis na trama. O fascínio dos alunos pela atuação do elfo foi surpreendente, pois ele era citado insistentemente por todos, ao contrário da escola particular, onde pouco foi dito sobre ele.

Na escola particular, quase $70 \%$ das respostas se referiram a personagens menos atuantes, como o Pippin e a Arwen, evidenciando que o comportamento falou mais que a ação.

Porém, um personagem foi tido como elemento de ligação entre ambas as escolas: o Aragorn. Mesmo tendo sido citado apenas por uma entrevistada na escola particular, todos os outros se lembraram bem dele e aprovaram suas atitudes na trama. O mesmo ocorreu na escola pública, onde mesmo aqueles que não disseram tê-lo como favorito o citaram como alguém marcante.

Sendo um personagem atuante não apenas nas cenas de batalha, mas também com muita presença nas cenas de questões pessoais e estratégicas, ele se fortificou, sendo um herói com grande carga dramática, fugindo do estereótipo de um herói intocável e prepotente, já muito repudiado pelo público atual. As características de liderança, amor, determinação, amizade foram as mais lembradas, e, inclusive, ele foi tido como aquele que apareceu para pôr em xeque a índole humana, o que mostra a carência do público de personagens mais humanos e desafiadores, que sofrem uma grande transformação interna e externa no decorrer da narrativa.

Gandalf também foi muito lembrado no decorrer da entrevista. Já era esperado que ele não fosse tido como preferido pelos jovens, por ser a voz da experiência e o orientador; ele foi tido mais como aquele que 
todos gostariam de ter ao lado, e não de personificar. Representado pela figura de um sábio, inclusive pela aparência, Gandalf foi tido como aquele que representava o bem em toda a sua magnitude, sendo o lado oposto do mal. Ele é uma figura simbólica de um deus, ou de um enviado dele, como de fato ele o é na história, o que é caracterizado por ser a personificação do self, a imagem do Velho Sábio, a voz da razão.

Com tudo isso, vê-se que as variações de personalidades e comportamentos são de suma importância para uma identificação do público com o filme, pois somente dessa maneira a pessoa pode se ver projetada em ações e características. Não é necessário ter uma gama tão grande de personagens numa história, e sim personagens que carreguem em si a força de um caráter, a versatilidade ao incorporar diferentes arquétipos com harmonia e uma grande presença na trama, o que fará dele alguém passível de identificação e admiração.

Arquétipos

\section{A anima}

No filme $O$ Senhor dos Anéis, a personagem Galadriel personifica o arquétipo da Anima, que é a personificação de todas as tendências psicológicas femininas na psique do homem - os humores e sentimentos instáveis, as intuições proféticas, a receptividade ao irracional, a capacidade de amar, a sensibilidade à natureza e, por fim, mas nem por isso menos importante, o relacionamento com o inconsciente.

A Anima, como um arquétipo de transformação, tem o poder de mostrar à pessoa o que é errado e o que é certo sob o seu ponto de vista, como uma mãe. M. - L. von Franz, discípula de Jung, confirma, quando diz que "nas manifestações individuais o caráter da anima de um

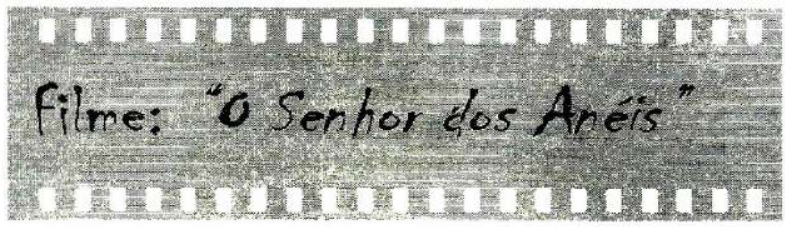

homem é, em geral, determinado por sua mãe"'.

Outro ponto importante é a característica dual desse arquétipo, $\mathrm{e}$ o von Franz afirma que "a anima (como a sombra) tem dois aspectos: o benévolo e o maléfico (ou negativo)"2. Assim como a sombra, o arquétipo da anima não vê diferenças entre o certo e o errado, nem a distinção entre bem e mal, defendendo seus próprios interesses. A anima bem estruturada pode assumir o papel de guia, ou de mediador, entre o mundo interior e o self, pode ser aquela que sintoniza a mente masculina com os seus valores interiores positivos, abrindo assim caminho a uma penetração interior mais profunda. Porém, como já foi dito, assim como ela pode ser boa, ela pode ser ruim. Por exemplo, um homem no qual a anima atue com cunho negativo pode se sentir desvalorizado, apático, com medo de acidentes, entre outras características negativas.

Foi perguntado aos entrevistados, primeiramente aos homens, o que eles achavam dessa personagem, para que sondássemos : éfeito psicológico que ela poderia ter provocado neles, mostrando assim a relação de cada um com a anima interna. As respostas foram diversas, sendo que algumas coisas foram bem semelhantes. A capacidade de a personagem ver 0 futuro e mostrar o caminho ao Frodo foi uma delas.

Os entrevistados citaram características associadas ao arquétipo ao descrever a personagem, como quando a chamaram de ambígua ou até mesmo de esquisita. Ficou claro, pelas respostas, que houve uma exteriorização dos arquétipos presentes no inconsciente
1 JUNG, Carl Gustav \& Franz, M. - L. von. O Homem e seus símbolos. $20^{a}$ ed. Rio de Janeiro: Nova Fronteira. p. 178.

${ }^{2}$ Idem 
deles: aqueles que disseram ter boa relação com os pais acentuaram aspectos positivos, ao contrário daqueles que tinham problemas com a família, principalmente no que diz respeito à confiança. Dentre, ninguém confiaria nela e dentre aqueles, até haveria confiança, mas não total. Quando a pergunta foi feita às mulheres, todas citaram apenas aspectos positivos em relação à personagem, inclusive no aspecto de confiança.

\section{Animus}

O animus é a personificação masculina do inconsciente na mulher, e que, assim com o a anima, tem também aspectos negativos, como a brutalidade, a indiferença e, a tendência à conversa vazia, às idéias silenciosas, obstinadas e más, e positivos, como o de lançar uma ponte para o self por meio da atividade criadora. Em O Senhor dos Anéis, outro elfo representa bem o que seria um animus projetado: o Elrond.

Pai da Arwen e um dos portadores dos anéis élficos, ele representa bem os lados "bom" e "mal" de uma pessoa. Apesar de ser um bom pai, como é verificado nas horas em que tanto ajuda a filha, não quer a sua união com um humano, por vários motivos, dentre eles o de ela ser imortal e ele não, e por já ter tido decepções muito grandes com os humanos em situações passadas.

Uma característica do animus é que, assim como a anima é moldada pela mãe, ele é basicamente influenciado pelo pai. "É o pai que dá ao animus da filha conviç̧ões incontestavelmente 'verdadeiras', irretrucáveis e de um colorido todo especial-convicções que nunca têm nada a ver com a pessoa real que é aquela mulher. Por isso, o animus, tal

${ }^{3}$ VOGLER, Christopher. A jornada do escritor: estruturas míticas para contadores de histónias e roteiristas. Rio de Janeiro: Ampersand Editora LTDA, 1997. p. 67. como a anima, pode, algumas vezes, tornar-se o demônio da morte".

Foi perguntado, primeiramente às personagem e todas levantaram aspectos ambíguos, de atitudes boas e outras ruins, associadas ao personagem. $\mathrm{O}$ fato de sua relação com a filha foi levantado diversas vezes, sendo que ele foi tido como um pai rigoroso, mas amoroso, duas características opostas associadas ao mesmo homem.

Todos os homens levantaram apenas aspectos positivos, tanto de sua relação paternal com a filha como de seu papel de rei.

\section{Velho Sábio, Mentor ou Self}

"Um arquétipo que freqüentemente encontramos nos sonhos, mitos e historias é o Mentor-em geral, uma figura positiva que ajuda ou treina o herói. $O$ nome que Campbell dá a essa força é Velho Sábio ou Velha Sábia. Esse arquétipo se expressa em todos aqueles personagens que ensinam e protegem os heróis e lhes dão certos dons. Pode ser Deus caminhando com Adão no Jardim do Éden, Merlin guiando o rei Arthur, a Fada Madrinha ajudando Cinderela, ou um sargento veterano dando conselhos a um recruta novato. Mas a relação entre o herói e o Mentor é uma das mais ricas fontes de entretenimento na literatura e no cinema" ${ }^{3}$.

O velho sábio é a figura da razão que, geralmente representada por um velho ou por um animal, surge na vida do herói para dar-lhe instruções de como lidar com os problemas que virão e que ele terá, mais cedo ou mais tarde, de enfrentar. Essa figura sábia seria a voz da consciência, aquela que nos guia, aquela que representa a totalidade absoluta da psique, diferentemente do ego, que constitui apenas uma pequena parte; isso tudo representa o self. mulheres o que elas achavam do
"O self pode ser definido como um fator de orientação íntima, diferente da personalidade 
consciente, e que só pode ser apreendido através da investigação dos sonhos de cada um. E estes sonhos mostram-no como um centro regulador, centro que provoca um constante desenvolvimento e amadurecimento da personalidade. Mas este aspecto mais rico e mais total da psique aparece, de início, apenas como uma possibilidade inata. Pode emergir de maneira insuficiente ou então desenvolver-se de modo quase completo ao longo da nossa existência; o quanto vai evoluir depende do desejo do ego de ouvir ou não as suas mensagens"4 .

O self aparece na linguagem onírica dos sonhos para dar conselhos ao ego, para que assim haja o processo de individuação, o que fará com que a pessoa crie a sua própria personalidade. Ele é a voz que destoa em relação ao ego, pois muitas vezes essa voz diz coisas que não queremos fazer, mas ela está lá, e sempre estará, por mais que gostemos ou não.

Todos os adjetivos dados pelos entrevistados caracterizam perfeitamente essa figura do self, quando eles o chamaram de sábio, líder, a pessoa que tinha a voz da razão, aquele que dava dicas e opiniões e até de psicólogo.

A imagem passada pelo mago é aquela que indica um ponto de equilíbrio, fazendo com que ele carregue uma grande responsabilidade consigo. Ele é o extremo da balança entre o bem e o mal. Sua figura é imprescindível para a harmonia dos personagens. Em relação aos espectadores, ele é o ponto de confiança, pois nele todos confiam e se sentem protegidos, é aquele que acalma, mesmo em cenas mais complicadas e pesadas.

Uma coisa ficou clara com toda a jornada do mago com a sociedade do anel: se não fosse a sua participação, nada teria dado certo, nem mesmo a identificação do público com o filme, pois as questões de confiabilidade e segurança teriam sido totalmente abaladas.

0 Herói

"A palavra herói vem do grego, de uma raiz que significa 'proteger e servir'. Um herói é alguém que está disposto a sacrificar suas próprias necessidades em beneficio dos outros".

"Em termos psicológicos, o arquétipo do Herói representa o que Freud chamou de ego - a parte da personalidade que se separa da mãe, que se considera distinta do resto da raça humana. Em última análise, um Herói é aquele que é capaz de transcender os limites e ilusões do ego mas, de início, os Heróis șão inteiramente ego, se confundem com o ego, o 'eu', com aquela identidade pessoal que pensa que é distinta do resto do grupo. A jornada de muitos Heróis é a história dessa separação da família ou da tribo, equivalente ao sentido de separação da mãe, que uma criança vivencia"s.

Existem vários tipos de heróis, que são classificados pela personalidade demonstrada durante a jornada e que podem ser divididos em: Inocente, o Órfão, o Mártir, o Caminhante, o Guerreiro, o Protetor, o que Busca, o Amante, o Destruidor, o Criador, o Governante, o Mágico, o Sábio, o Bobo.

Vários personagens encarnaram a imagem de herói no filme, porém um se destacou dentre todos os outros por sua desenvoltura, por sua importância e, principalmente, pelo crescimento de sua persona: Aragorn.

Ele poderia ser classificado como o caminhante, o guerreiro, o protetor, o que busca, o amante, o governante, entre outras subclassificações, mas o fato mais importante de sua jornada é o seu
${ }^{4}$ JUNG, op. Cit., p.162.

${ }^{5}$ VOGLER, op. Cit., p. 53. 
crescimento. Ele entra na narrativa como aquele viajante desconhecido e misterioso, que ninguém respeita e nem tem com ele intimidade, alguém sem passado e provavelmente sem futuro. Ele é chamado apenas por um nome inventado pelos outros para caracterizá-lo: ele é o Passolargo. Com o passar da jornada, ele se revela um grande homem, aquele que seria o verdadeiro líder, aquele que viria a se tornar o rei. Camilla, uma das entrevistadas, lembrou-se disso, dizendo que, no início, ele era misterioso, com uma personalidade estranha.

A riqueza de sua personalidade o fez carismático e lembrado pelos entrevistados, que não apenas lembravam de suas atuações nas cenas de batalha, mas também de seu amor por Arwen, de seu carinho por seus amigos e de sua humildade, mesmo depois de ter se tornado rei.

Uma coisa muito lembrada foi o seu passado, principalmente no que está relacionado aos seus antepassados e ao medo de o personagem cometer os mesmos erros já cometidos em outras ocasiões. Essa preocupação foi tida como mais relevante do que o inimigo em si, que seria Sauron. Não é comum a construção de um herói que tenha medo de algo, mas a superação de traumas faz do personagem alguém maior, de mais credibilidade e confiança, o que aconteceu no momento em que ele negou o anel, no final do primeiro filme, vencendo o maior de seus medos.

Essa é a função dos heróis, como diz Margaret Mark: "Na vida cotidiana, esses poderosos arquétipos proporcionam uma estrutura capaz de liberar, nas pessoas comuns, a capacidade de se erguer para enfrentar os desafios, correr riscos, quebrar as regras e transformar as suas vidas"6.

O Herói é aquele que vai agir; diferentemente do sábio, que dá as dicas, ele é o ego que escuta o self, por isso também possui um alto grau de identificação com essa figura, pois ele representa a nossa real vontade, independentemente das conseqüências, diferindo do velho sábio, que indica apenas o que é certo. "O arquétipo do Herói representa a busca de identidade e totalidade do ego. No processo de nos tornarmos seres humanos completos e integrados, somos todos Heróis, enfrentando guardiãs e monstros internos, contando com a ajuda de aliados. $\mathrm{Na}$ busca de explorarmos nossa própria mente, encontramos professores, guias, demônios, deuses, companheiros, servidores, bodes-expiatórios, mestres, sedutores, traidores e auxiliares, como aspectos de nossas personalidades ou como personagens de nossos sonhos. Todos os vilões, pícaros, amantes, amigos e inimigos do Herói podem ser encontrados dentro de nós mesmos. A tarefa psicológica que todos enfrentamos é a de integrar essas partes separadas em uma entidade completa e equilibrada. $\mathrm{O}$ ego - isto é, o Herói que acha que é separado de todas essas partes de si mesmo - deve incorporá-las para se tornar um ser integral"?.

\section{O Pícaro}

O Pícaro, ou Bobo da Corte, é o arquétipo que incorpora as energias da vontade de pregar peças e do desejo de mudança. Uma figura comum nos contos de fadas, ele tem a função de quebrar a tensão encontrada na ação, por meio de suas palavras ou ações.

"No drama, o Pícaro serve a todas essas funções psicológicas, e mais à função dramática de alívio cômico. Uma tensão sem alívio, o suspense e o conflito podem ser exaustivos emocionalmente e, mesmo nos dramas mais carregados, a atenção da platéia se reaviva com momentos de 
gargalhada. Uma velha regra do teatro assinala essa necessidade de equilíbrio: Faça-os chorar muito, faça-os rir um pouco"s.

Geralmente, um ou alguns personagens são designados para essa função, pois sem eles a narrativa se tornaria cansativa e o processo de catarse, muito mais complicado, não havendo uma entrega, por parte do público, ao filme.

Uma das entrevistadas disse ter Pippin como personagem favorito, explicando que ele, mesmo não aparecendo muito, era alguém mais alegre e descontraído, e que, com isso, não ficava preso ao objeto central da trama, o anel, nem a suas conseqüências, como destruição e problemas.

$\mathrm{O}$ que ela disse é exatamente o que os personagens que personificam o Pícaro têm de fazer: ser alegre, divertido e se mostrar um pouco afastado de tudo, sendo um ponto de descanso. Segundo Mark, o desejo básico do bobo da corte é o de viver o momento presente, com alegria total; com a meta de divertir-se e alegrar o mundo; tem medo de aborrecer-se ou ser maçante; tem o dom da alegria ${ }^{9}$.

\section{A Sombra}

Antes de qualquer coisa, a sombra não é má, mas apenas uma parte do nosso inconsciente menos conhecida, com propósitos e vontades não claras.

Pode-se dizer que em cada um de nós existe uma parte da personalidade à que preferimos não olhar muito de perto, e que por diversas razões ficam escondidas, em uma parte escura, não visível aos olhos do consciente. Mas essa parte se expressa em imagens oníricas quando sonhamos; é o que Jung denominou de "a realização da sombra".

A maior tendência das pessoas é a de projetar essas características negativas naqueles que estão perto, por um efeito de compensação, ao pensar que ninguém irá perceber, que todos também são assim.

Se o herói é considerado como o ego de nossa psique e se a sombra representa o grande desafio a ser enfrentado (que pode ser representado pela figura de alguém de caráter oposto ao mostrado pelo herói, com características denominadas de más), o momento em que ocorre o confronto, ego-sombra ou heróidesafio, é o instante no qual o lado consciente (ego ou herói) toma consciência de suas fraquezas, que estão sendo postas à prova, no caso, se ele não vencer os próprios fantasmas, certamente perderá a guerra.

O principal herói da trama é Aragorn, atormentado por um estigma do passado que carrega consigo, um estigma que lhe diz que não será capaz de destruir o anel, por causa da ganância que ele carrega em seu sangue, herdado de seus antepassados.

Essa é a primeira sombra que o herói precisa enfrentar, igualmente para o Frodo, que deve vencer o estigma de ser baixo e fraco, ou para Éowyn, por ser uma mulher. Apenas com a vitória sobre essas partes da psique que os limitam eles serão capazes de atingir um novo patamar, que se encontra bem acima do universo de suas vidas.

Essa primeira vitória é muito representativa e gradual, sendo associada ao crescimento dos personagens na narrativa, crescimento este lembrado por todos os entrevistados. Essa luta constante com os próprios temores é o que faz dos personagens objetos de contemplação, pois se eles conseguem, por que eu não conseguiria?

Nesse estágio, a sombra é projetada, vemos em outras pessoas as coisas que não conseguimos ver em nós mesmos. Nesse momento, a figura do inimigo aparece, e o herói vê em alguém uma figura que
${ }^{8}$ Ibid., p. 108.
${ }^{9}$ MARK, op. cit., p. 204. 


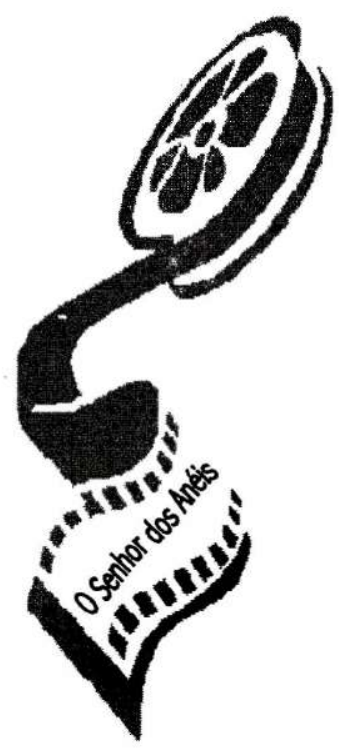

${ }^{10}$ JUNG, op. cit., p. 176. representa o mal, mas esse mal é aquilo que ele carrega em si, mas que não consegue ver. Ele luta contra um espelho, no qual a imagem refletida é um ponto dele que ele mesmo não consegue enxergar, mas que está lá.

$\mathrm{O}$ fato de o principal inimigo e antagonista da trama ser um olho mostra tudo contra o que o herói luta, em primeiro lugar, a ganância. A visão, como é tida em várias religiões e culturas, é o sentido do pecado, aquele que primeiro nos incita a fazer algo contra a nossa percepção de certo ou errado, aquele que nos faz negligenciar as respostas do superego.

Isso faz claro o sentido de Sauron, pois ele é aquele que representa o mal de cada um, contido em apenas uma imagem, uma representação.

Outras características foram ditas, como ambição, opositor, aquele que corrompe, a personificação do mal, todas atribuídas à sombra, por sua característica de oposição ao self. "Pode ser que o self queira que o ego faça uma escolha livre; ou que talvez o self, para manifestar-se, dependa da consciência humana e de suas decisões. Quando surge este tipo de problema ético ninguém pode verdadeiramente julgar os atos alheios. Cada homem tem de enfrentar o seu próprio problema e tentar determinar o que lhe parece mais certo"10. Nesse instante, Gandalf não mais aconselha, deixando que os Heróis tomem as suas próprias decisões.

As manifestações da sombra não findam aqui, pois ela também está presente em paisagens, geralmente lugares escuros, sombrios, frios e desconhecidos. Mas agora, diferentemente da personificação da sombra, esses lugares apresentam a porta da inconsciência em si, que muitos preferem negligenciar, mas é só atravessando essa escuridão que outro limiar será alcançado, bem superior - e melhor - ao que foi deixado para trás.

Duas perguntas foram feitas aos entrevistados, pensando-se nessa característica da sombra: primeiro, em que lugar da Terra Média eles não viveriam, e outra, se eles sentiram medo em algum momento do filme.

Em relação ao lugar onde não viveriam, a resposta já era esperada: $100 \%$ deles disseram que não morariam em Mordor, por ser frio, escuro e tenebroso (características já ditas anteriormente).

Foi perguntado se em algum momento os entrevistados sentiram pena de alguém ou de algo e se sentiram medo, e as respostas mostram claramente a visão dos entrevistados em relação à sombra. $\mathrm{Na}$ escola pública, a maior parte das respostas lembrou cenas nas quais as ações aconteceram dentro de cavernas ou florestas.

$\mathrm{Na}$ escola particular, cenas envolvendo esses lugares também foram maioria, sejam elas o vulcão, onde Frodo destruiu o anel, as cavernas - a do primeiro filme, na mina dos anões ou a do terceiro filme, quando Aragorn vai pedir auxílio aos fantasmas -, ou as florestas, como a de Fangorn, habitat dos ents.

Porém, uma resposta se mostrou a mais interessante: a que um entrevistado descreve a figura do inconsciente e, respectivamente, da sombra, enquanto descreve uma cena do filme. Ele diz que quando os personagens entram na caverna, no primeiro filme, onde no início estava tudo quieto, de repente aparece um exército de orcs querendo matá-los. Continua dizendo que, logo depois de cenas escuras e nervosas, há um céu azul e lugares que transmitem a sensação de paz e calmaria, dandolhes alívio, apesar de saberem que ainda há novas batalhas pela frente. Ele acha que isso é bom, por darlhes energia, e, por fim, diz que todos os personagens evoluem, entrando de um jeito e saindo melhor. 
Essa é a representação ideal do que é o medo inicial do desconhecido (da sombra), o enfrentamento e depois a salvação, a recompensa. O lado desconhecido e ameaçador do inconsciente é escuro e muito silencioso; porém, ao ser atiçado, ele se revolta, fazendo com que verdades, que eram omitidas, venham à tona.

A imagem da sombra sempre será tida como elemento de oposição, como antagonista, aquele que é o lado oposto da balança, mas que tem uma função que passa o sentido de "maldade". Ela existe para que o protagonista ou herói vença seus próprios medos e cresça, tornando-se alguém mais digno e respeitado; assim, ele se torna um elemento de modificação, um arquétipo de transformação.

\section{Conclusão}

Conclui-se, com este trabalho, o quanto um estudo bem feito e estruturado dos mitos pode fazer com que entendamos outras áreas do conhecimento humano, como, neste caso, a comunicação. Partindo do pressuposto de Jung, de que todos temos resquícios do inconsciente coletivo, acha-se então um bom caminho para alcançar os objetivos da mídia moderna, sejam eles quais forem.

É uma pesquisa que se destina a todos, seja àqueles que enviam ou aos que recebem as mensagens da mídia. Seja para um conhecimento ou um entendimento de como certas coisas nos fascinam e outras não, seja para compreender como usar de imagens e símbolos e saber qual será a sua repercussão, tendo mais certeza do que vincular antes de fazê-lo.

\section{Abstract}

This research aims at studying the behavior of public in general regarding the collective unconscious images, that according to Jung, are in everyone's mind, and do not take social class, religion, race, etc as a matter of choice. These archetypical images are responsible for the psyche structuration, establishing ways to go on, and how to go through them. For a better understanding, an interview was made with students from public and private schools. The data collected from the survey was processed according to their classification, age, and social class; which resulted in a final parallel between such information.

Keywords: Myths, Archetypes, Narrative Construction, Lord of the Rings, Archetypical Images, Psyche.

\section{Referência}

BOYER, Régis. Dicionário de Mitos Literários: Arquétipos. $3^{\mathrm{a}}$ ed. Rio de Janeiro: José Olympio, 2000.

JUNG, Carl Gustav. Os Arquétipos e o Inconsciente Coletivo. Petrópolis: Vozes, 2000.

SELLIER, Phillippe. Dicionário de Mitos Literários: Heroísmo (o modelo - da imaginação). $3^{\mathrm{a}}$ ed. Rio de Janeiro: José Olympio, 2000.

CAMPBELL, Joseph. O Poder do Mito. $16^{a}$ ed. São Paulo: Palas Athena, 1998. CAMPBELL, Joseph. As Máscaras de Deus: Mitologia Primitiva. $6^{\mathrm{a}}$ ed. São Paulo: Palas Athena, 2003.

CAMPBELL, Joseph. O Herói de Mil Faces. $7^{a}$ ed. São Paulo: PensamentoCultrix, 2002.

MARK, Margaret \& PEARSON, Carol. O herói e o fora-da-lei. Como construir marcas extraordinárias usando o poder dos arquétipos. $1^{\text {a }}$ ed. São Paulo: Pensamento-Cultrix, Meio e Mensagem; 2004.

VOGLER, Christopher. A jornada do escritor: estruturas míticas para contadores de histórias e roteiristas. Rio de Janeiro: Ampersand Editora LTDA, 1997.

JUNG, Carl Gustav \& Franz, M. -L. von. $O$ Homem e seus simbolos. $20^{\text {a }}$. ed. Rio de Janeiro: Nova Fronteira. s/d.

Data do Recebimento: 24/08/2005

Data do aceite: 13/09/2005 